\title{
Temperature Dependency of Beremin’s Parameters for 20MnMoNi55 Material
}

\author{
B. K. Dutta, S. Guin, M. K. Sahu and M. K. Samal \\ Reactor Safety Division, Bhabha Atomic Research Centre, Trombay, Mumbai - 400085, India
}

\begin{abstract}
The temperature dependency of Beremin's parameters has been investigated for 20MnMoNi55 material. Tensile tests have been conducted on grooved specimens at temperatures $-70^{\circ} \mathrm{C}$ and $-100^{\circ} \mathrm{C}$. Thirty specimens have been tested in each set. Image processing technique has been used for measuring diametral contraction by processing images taken on-line during experiments. Subsequently, the analytical studies have been carried out to determine Beremin's parameters using the statistical variation in load v/s diametral contraction at fracture. For this purpose, finite element analyses have been carried out for each specimen to determine Weibull stresses. The experimental probability of failure of each specimen has been calculated by ranking them based on the diametral contraction at the time of fracture. Such a table along with the Weibull stresses are used in the equations derived using “maximum likelihood method” to derive the Beremin's parameters. The temperature dependency of these parameters is then investigated for the present material.
\end{abstract}

\section{INTRODUCTION}

One of the major concerns emerging out of irradiation on structural material is embrittlement. Irradiation embrittlement is manifested by an increase in ductile brittle transition temperature (DBTT) of ferritic steel. According to USNRC Regulatory Guide 1.99 Rev. 2, the shift in DBTT (in ${ }^{0} \mathrm{~F}$ ) as a function of the neutron fluence is given by:

$$
\triangle D B T T=[C F] \times f^{(0.28-0.1 \log f)}
$$

Here CF is a function of the weight percentages of copper and nickel in the material and $\mathrm{f}$ is the fluence in the unit of $10^{19}$ $\mathrm{n} / \mathrm{cm}^{2}$.

Components like reactor pressure vessels (RPV) which use ferritic steel operate under high neutron flux over considerably period of time. It is essential to assess the structural integrity of the irradiated RPV subjected to different degree of fluence under accidental scenarios. One such analysis scenario involves occurrence of 'loss of coolant accident' (LOCA), followed by a delayed appearance of emergency-core-cooling system. The rapid cooling of the vessel material can bring down the temperature to below ductile-brittle transition temperature under the presence of large scale tensile stresses. Under such condition, the micro-cracks in the component subjected may lead to unstable cleavage fracture. Knowledge on such fracture behavior of the RPV material at transition temperature is mandatory to quantify the inherent safety margin available under these undesirable events.

\section{BACKGROUND THEORY}

The mechanism of cleavage fracture in reactor pressure retaining material is significantly different from ductile fracture. The cleavage fracture in a material usually originates from micro-cracks, which are formed by different mechanisms. The micro-cracks are formed due to a non-homogeneous distribution of plastic deformation within the grains, called slip-initiated cleavage. The cracked grain boundary carbides also are the sources to originate the micro-cracks. This occurs when the stress normal to the planes of the carbide particles is sufficiently high. The fracture takes place by the formation of micro-cracks and their subsequent extension with little global plastic deformation. The cleavage process is stress controlled and consumes little deformation energy and hence, the crack grows unstably fast. In such case the local fracture criterion is generally based on a critical cleavage stress.

Based on the weakest link assumption [1] and Weibull statistics, Beremin developed a model for the analysis of cleavage fracture process [2]. Present work is based on two-parameter Weibull statistics. These parameters, termed Beremin's parameters, are determined using experimental fracture data and finite element (FE) analysis and are essential to predict probability of cleavage fracture in a reactor component. Experiments are done to obtain load-deformation data at failure and FE analyses are done to get the stress distribution in the test specimen at failure. The failure probability is given by:

$$
P_{f}=1-\exp \left[-\left(\frac{\sigma_{w}}{\sigma_{u}}\right)^{m}\right]
$$

Here, $\sigma_{\mathrm{u}}$ is the scaling parameter describing the mean value of $\sigma_{\mathrm{w}}$ for a failure probability value of $63.2 \%$ and ' $\mathrm{m}$ ' is the Weibull exponent or shape parameter quantifying the slope of $\mathrm{P}_{\mathrm{f}}$. 
The Weibull stress $\sigma_{\mathrm{w}}$ is defined as:

$$
\sigma_{w}=\left[\sum_{i=1}^{n_{p l}}\left(\sigma_{I}^{(i)}\right)^{m} \frac{V_{i}}{V_{0}}\right]^{\frac{1}{m}}
$$

Here, $\sigma_{\mathrm{I}}$ is the maximum principal stress, $\mathrm{n}_{\mathrm{pl}}$ is the total number of elements undergone plastic deformation, $\mathrm{V}_{\mathrm{i}}$ is the volume of the $\mathrm{i}^{\text {th }}$ yielded element and $\mathrm{V}_{0}$ is a reference volume taken as $10^{-3} \mathrm{~mm}^{3}$ in the present work.

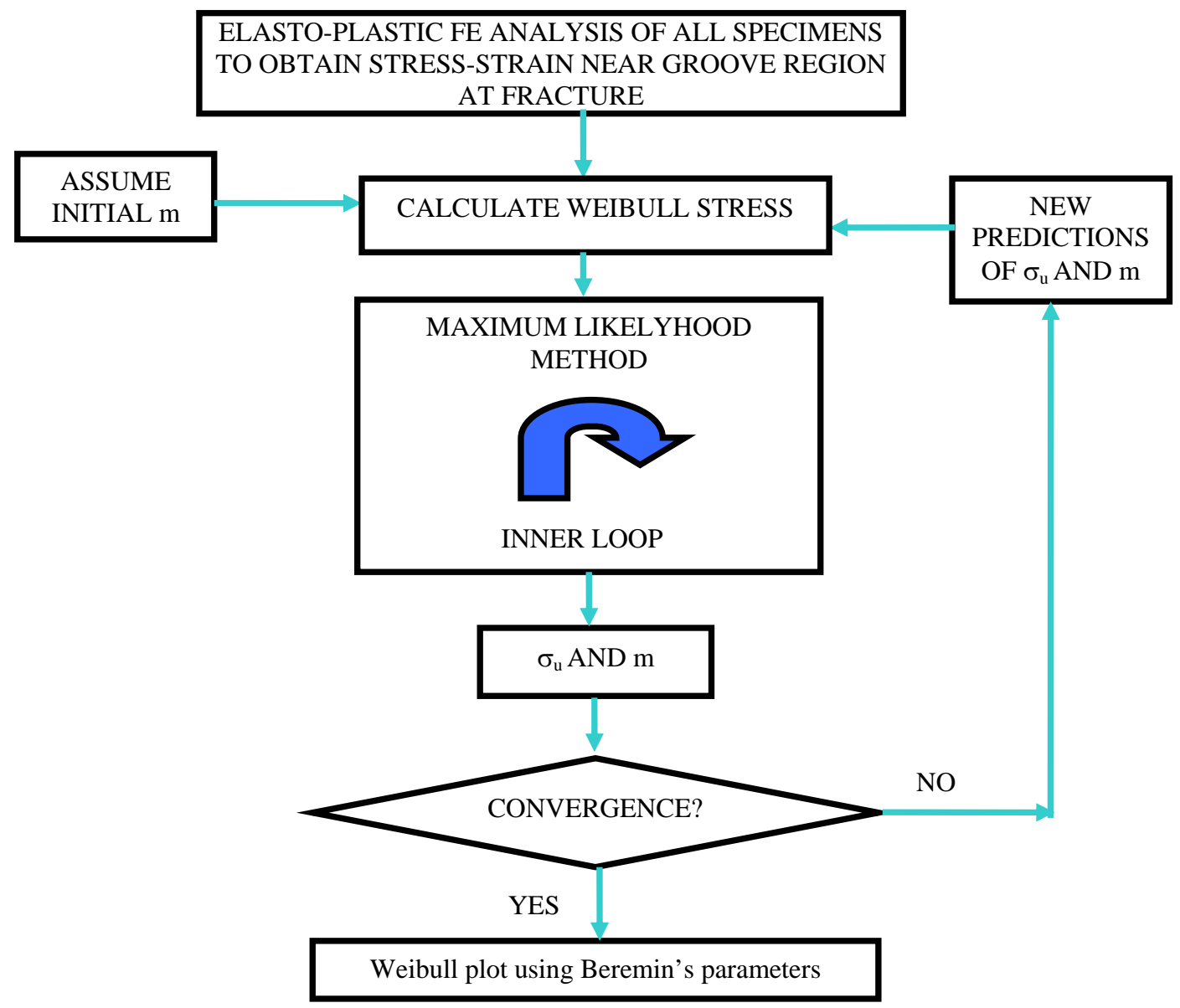

Fig.1 Algorithm to compute Beremin’s parameters

In maximum likelihood method [3, 4], the values of the two parameters $m$ and $\sigma_{u}$ are adjusted to have maximum probability of occurrence of experimental results. This is equal to the probability that all $\sigma_{\mathrm{w}}$ values occur simultaneously. The likelihood function is given by the product of all the individual fracture probabilities. The expressions for $\sigma_{\mathrm{u}}$ and $\mathrm{m}$ are then obtained by maximizing this likelihood function. The principle of maximization gives the following two nonlinear equations, where $\mathrm{N}$ is the total number of specimens.

$$
\frac{N}{m}+\sum_{i=1}^{N} \ln \left(\sigma_{w_{i}}\right)-N \cdot \frac{\sum_{i=1}^{N}\left(\sigma_{w_{i}}\right)^{m} \cdot \ln \left(\sigma_{w_{i}}\right)}{\sum_{i=1}^{N}\left(\sigma_{w_{i}}\right)^{m}}=0
$$




$$
\sigma_{u}=\left[\frac{1}{N} \sum_{i=1}^{N}\left(\sigma_{w_{i}}\right)^{m}\right] \frac{1}{m}
$$

These two nonlinear equations are solved iteratively to arrive at the values of $\mathrm{m}$ and $\sigma_{\mathrm{u}}$. The computational procedure in the form of an algorithm is shown in Fig. 1.

\section{EXPERIMENTAL DETAILS}

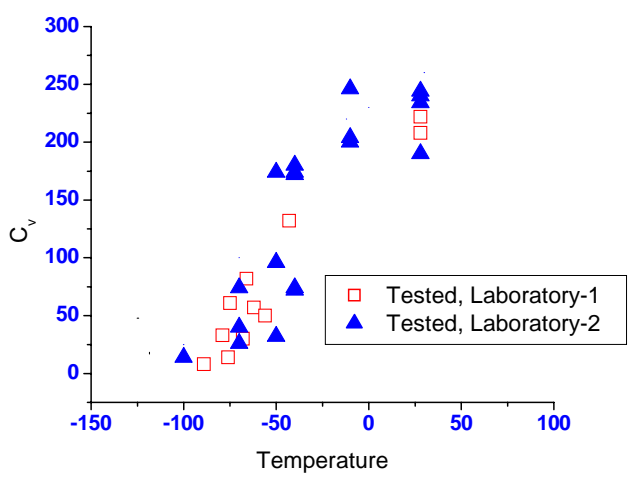

Fig. 2 Variation of Charpy energy with temperature

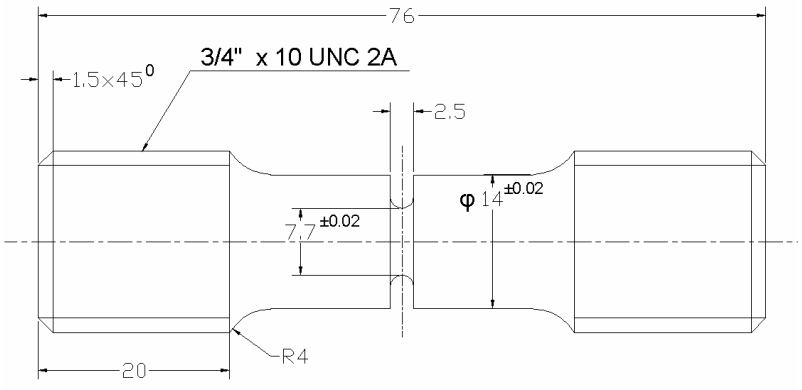

Fig.3 Dimensions of Grooved Tensile Test Specimen

Specimens of ferritic steel 20MnMoNi55 were tested in two different laboratories to get the variation of Charpy energy as a function of temperature. The results are shown in Fig. 2. Here $\mathrm{C}_{\mathrm{V}}$ represents Charpy energy. It is seen that the temperatures $-70^{\circ} \mathrm{C}$ and $-100^{\circ} \mathrm{C}$ falls in the transition region, close to lower shelf temperature. Hence the present set of experiments is done to determine Beremin's parameter at these two temperatures.

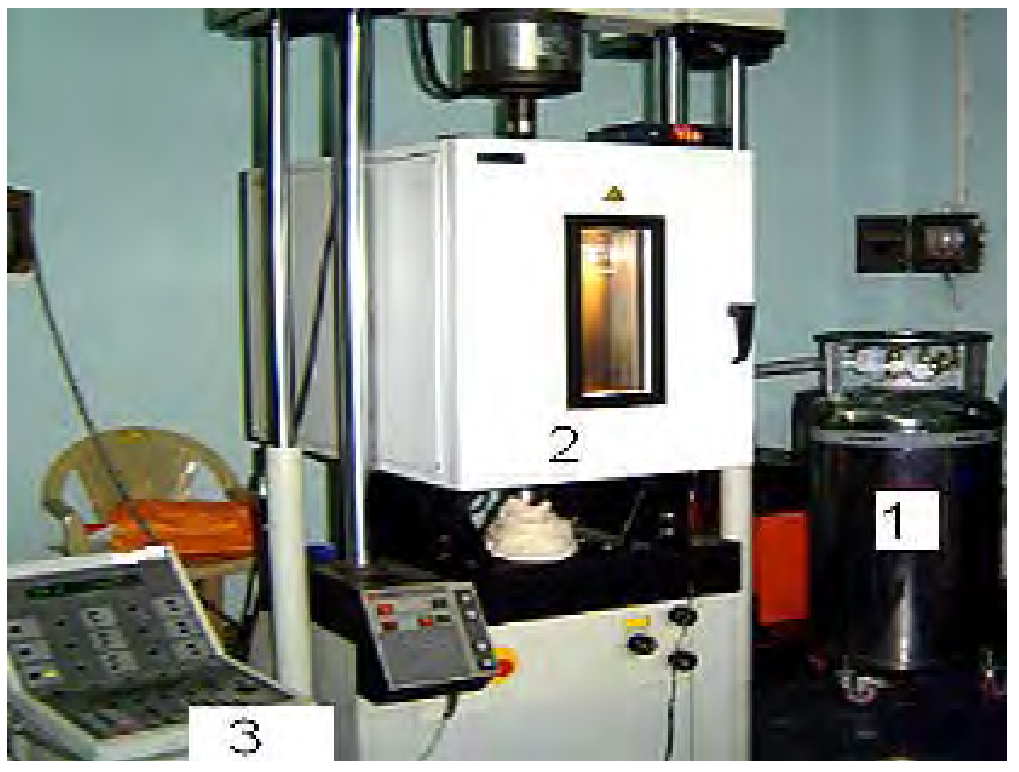

Fig.4 Experimental set-up (1-Liquid nitrogen cylinder, 2-Cryogenic chamber, 3 - Control panel)

An elaborate and dedicated test program has been planned. Since nature of the cleavage fracture is inherently statistical, a large number of specimens have been tested at each temperature. Round notched tensile specimens (RNTS) have been used to impose triaxial state of stress during the tests. Fig. 3 shows the specimen dimensions. It has a groove diameter of $7.7 \mathrm{~mm}$ and notch radius of $1.25 \mathrm{~mm}$. In all, $60 \mathrm{RNT}$ specimens (30 at each of $-70^{\circ} \mathrm{C}$ and $-100^{\circ} \mathrm{C}$ ) have been tested, using vaporized liquid nitrogen as cryogenic medium. All the experiments have been conducted under displacement controlled loading conditions. The load-displacement data were directly measured from the instrumentations provided in the machine. 
Images of the specimens at grooved region were taken at regular intervals during tests using high resolution digital camera. The images are used latter to calculate the contraction in diameter as a function of load. Image-processing technique has been used for this purpose, which is explained in the following. Fig. 4 shows the arrangement of the experimental setup.

Strain was applied at a rate of $2 \times 10^{-4}$ per sec. The temperature inside the experimental chamber was controlled by maintaining proper flow rate of vaporized nitrogen into it, using semiconductor thermocouples and attached sensors. The loading was provided through hydraulic servo-mechanism, using embedded control panel and controlling software.

\section{MATERIAL PROPERTIES}

Smooth tensile specimens made of ferritic steel 20MnMoNi55 were tested to generate the nominal stress-strain data. True stress-strain plots were obtained by the following procedure:

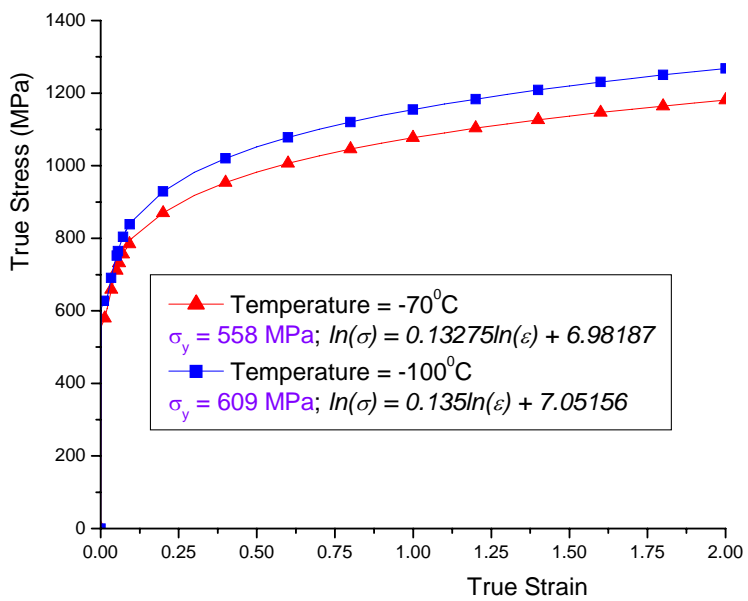

Fig.5 True stress-strain curves for 20MnMoNi55 at test temperatures

From the nominal stress-strain data, true stresses and strains have been found out up to the ultimate stress, using the following standard relationships.

$$
\varepsilon=\ln (1+e) ; \quad \sigma_{t}=\sigma(1+e)
$$

Here, $\varepsilon, \mathrm{e}, \sigma_{\mathrm{t}}$ and $\sigma$ are true strain, engineering strain, true stress and engineering stress respectively. A set of true stress-strain data near and before the ultimate stress is used to fit a polynomial of following type for the purpose of extending the data beyond ultimate stress.

$$
\ln (\sigma)=c_{1} \ln (\varepsilon)+c_{2}
$$

Fig. 5 shows the true stress-strain curves for the material at $-70^{\circ} \mathrm{C}$ and $-100^{\circ} \mathrm{C}$. The Poisson's ratio (v) and Young's modulus (E) of the material are taken as 0.3 and $210 \mathrm{GPa}$. The temperature variations of these parameters are neglected.

\section{IMAGE ANALYSIS AND RESULTING CURVES}

The variation in load with diametral contraction is obtained by using the measured load and corresponding image at grooved region. An in-house image processing code has been used for this purpose. Fig. 6 illustrates the processing methodology adopted, using a sample test case. Following are the steps used to get the diametral contraction.

a) Two vertical lines, each on the opposite diametral edges of the un-grooved segment, are marked.

b) Corresponding pixels of these two lines are used to calculate the scale, i.e., $\mathrm{mm} /$ pixel, since the un-grooved diameter is measured and known prior to the test.

c) Another vertical line, tangent to the groove at the smallest radius, is marked and the corresponding pixel number is noted.

d) The diameter of the groove is now calculated using the scale obtained in step (b).

e) This groove-diameter is subtracted from the initial groove-diameter to get the diametral contraction.

For each and every test, the images have been processed using this procedure at large number of load steps. It has been found that, there is a variation in the initial grooved diameters of different specimens due to fabrication tolerance. Hence the results based on actual diameters were normalized with respect to an average diameter to avoid any statistical variation due to this 
factor. The average diameter of the specimens for tests at $-70^{\circ} \mathrm{C}$ and $-100^{\circ} \mathrm{C}$ are respectively $7.21 \mathrm{~mm}$ and $7.34 \mathrm{~mm}$. The calculated load v/s diametral contraction curves are shown in Fig. 7.
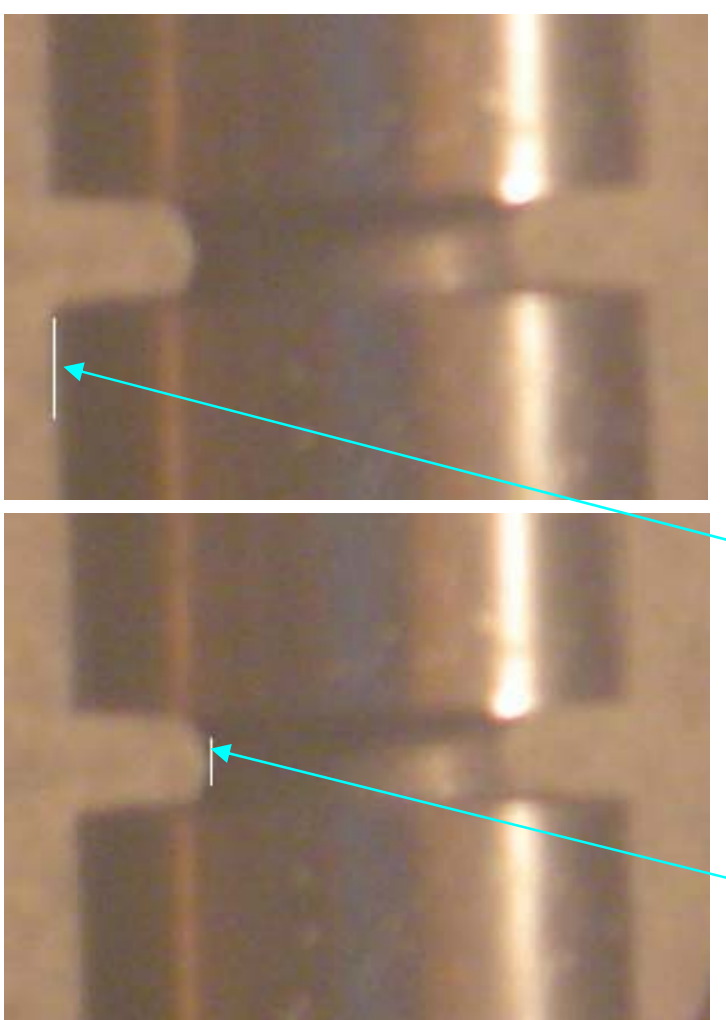

Fig.6 Steps in image processing technique to calculate the groove diameter during test
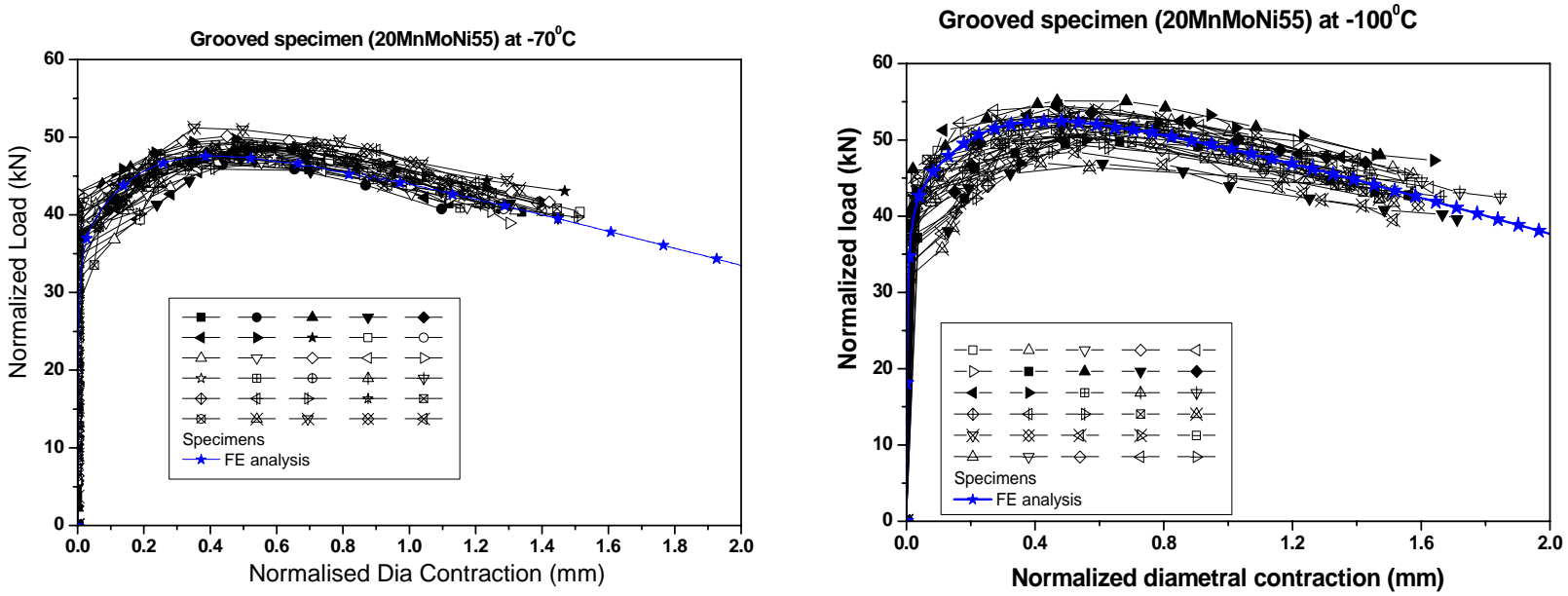

Fig.7 Load vs. Diametral contraction curves for tensile specimens at two different cryogenic temperatures

\section{ANALYSIS DETAILS}

Elastic-plastic FE analyses of the specimens have been carried out to get the stress distribution at various loads. Inhouse codes FEMSHAPE and MADAM have been used for modeling, meshing and elasto-plastic analyses of the specimens respectively. Eight node axi-symmetric isoparametric elements have been used in modeling. The mesh size used near the notch is $50 \mu \mathrm{m}$, to get the stresses at critical region accurately. Fig. 8 shows the mesh of the specimen as well as a zoomed 
view of the mesh at grooved region. Computed load v/s diametral contraction curves are superimposed in Fig. 7, showing fair amount of matching between the experimental and FE results.

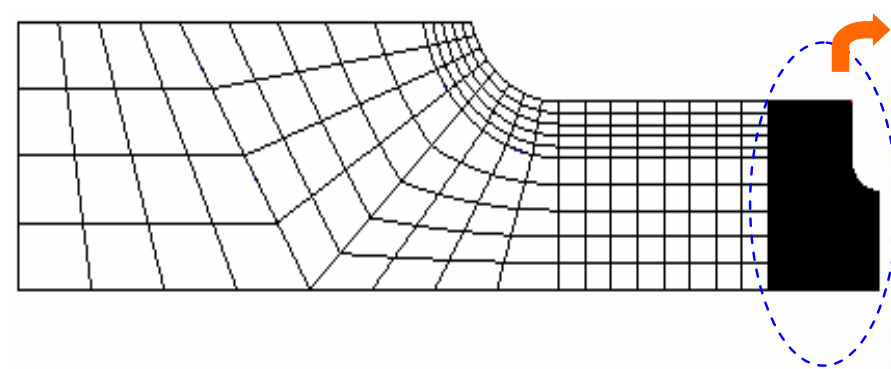

(a)

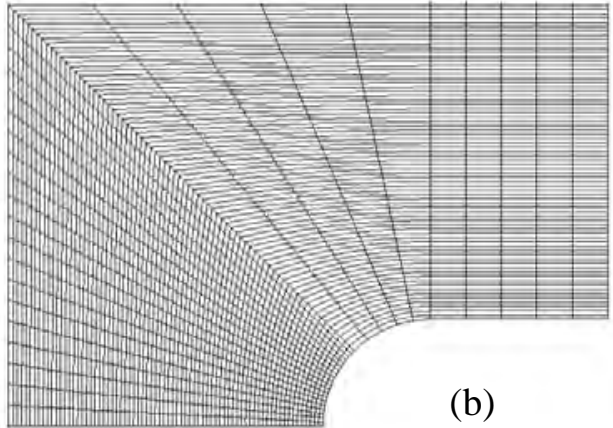

(b)

Fig.8 FE mesh of the specimen (a) Full specimen (b) Fine mesh near the grooved region (rotated $90^{\circ}$ )

Using this type of mesh and the material properties stated earlier, Beremin's parameters can be calculated at temperatures $-70^{\circ} \mathrm{C}$ and $-100^{\circ} \mathrm{C}$. Experimental results show that a fair amount of ductility is retained in the material at both these temperatures. Hence, Beremin's parameters for the material at these two temperatures are calculated by ranking the specimens in order of diametral strain at failure.

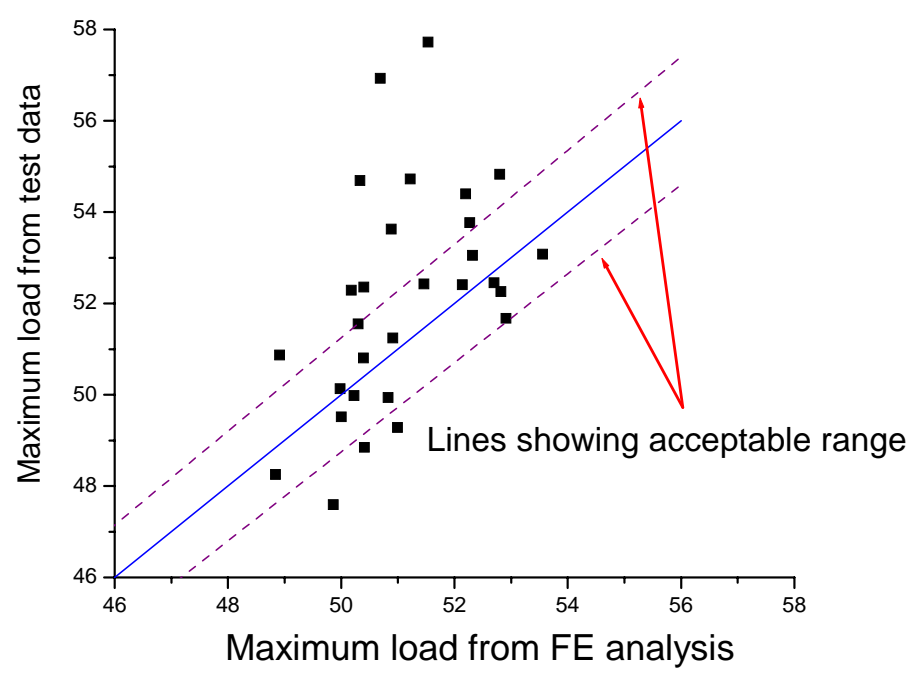

Fig.9 A Comparison of measured and computed maximum loads

A variation in the maximum load is noted between different specimens. Such unexpected variation in the maximum load even after normalization can be attributed to some extent in the variation of material stress-strain curves from specimen to specimen. It was then decided to short list the specimens in which the variation in maximum load is small and can be attributed to the variation in stress-strain properties. Elastic-plastic FE analyses were carried out for each specimen separately taking into consideration the initial groove diameter $\left(D_{i}\right)$ using the stress-strain curve of Fig. 5. A comparison between the maximum load obtained from FE analysis and measured data is shown in Fig. 9. It may be seen that about $60 \%$ of the specimens have maximum load within $\pm 2.5 \%$ of computed maximum load. Only these specimens were then selected for further processing.

For these short listed specimens, the stress-strain properties were slightly adjusted case-by-case to get computed maximum load close to the measured values. The Weibull stresses at fracture are then computed from these analyses for each specimen separately. Similar strategy was adopted for both the test temperatures. Fig. 10 shows a few sample plots of load v/s diametral contraction curves obtained experimentally and analytically after such minor modifications in stress-strain properties case-by-case. 

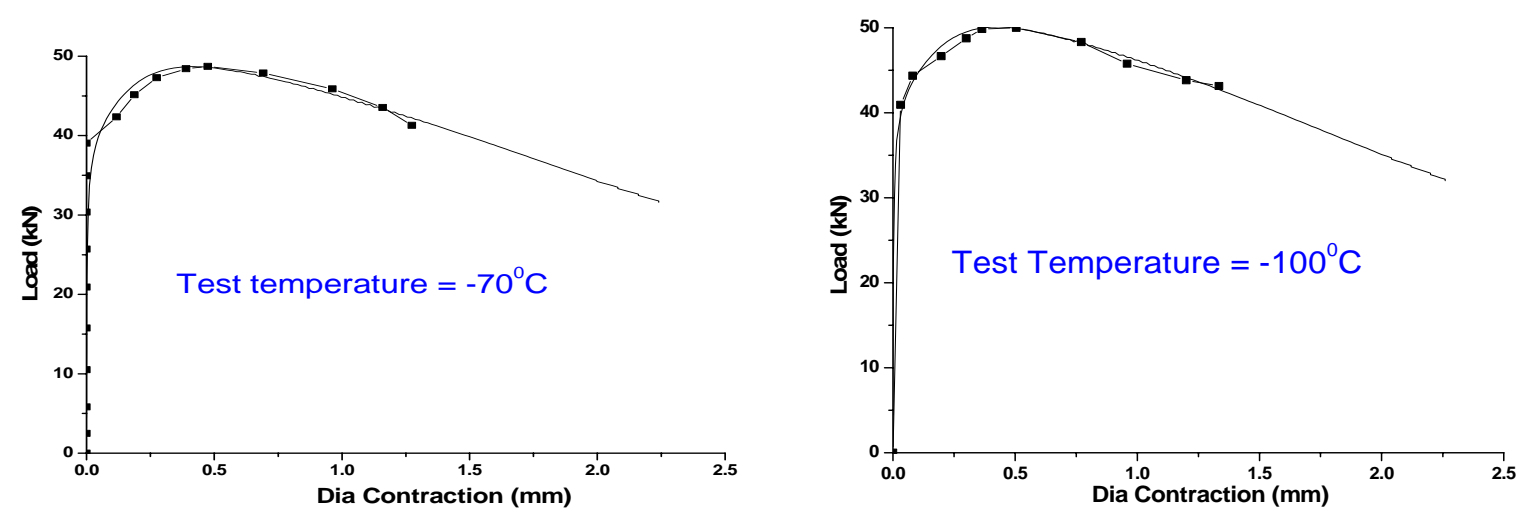

Fig.10 Typical load v/s diametral contraction curves after specimen-specific modifications in stress-strain properties RESULTS

The selected specimens were ranked in increasing order of the diametral strain at groove region, i.e. $\Delta \mathrm{D}_{\mathrm{i}} / \mathrm{D}_{\mathrm{i}}$, where $\Delta D_{i}$ is the decrease in groove diameter at fracture. Beremin's parameters were calculated using these specimens. The shape parameter $\mathrm{m}$ was corrected using the plot of Fig. 11 to take into consideration the finite number of specimens [6]. Table-1 shows the values of Beremin's parameters at two cryogenic temperatures after such corrections. Fig. 12 depicts the experimental and computed plot of $\mathrm{P}_{\mathrm{f}} \mathrm{v} / \mathrm{s} \sigma_{\mathrm{w}}$, at two temperatures.

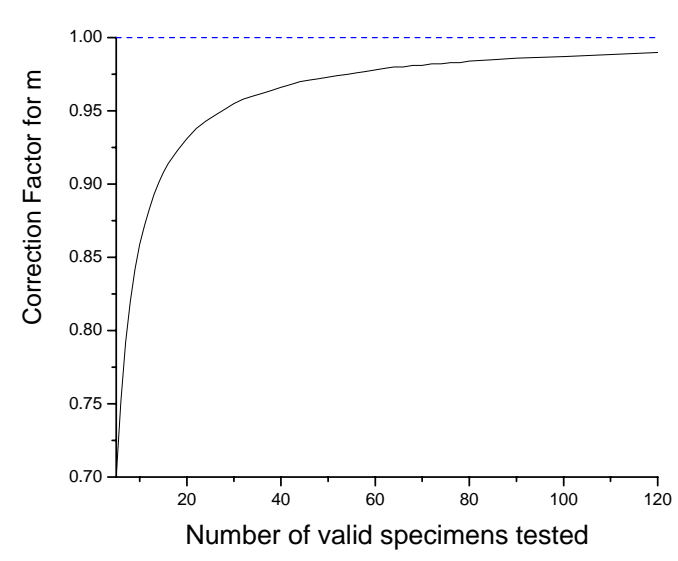

Fig.11 Correction factor for shape parameter (m)

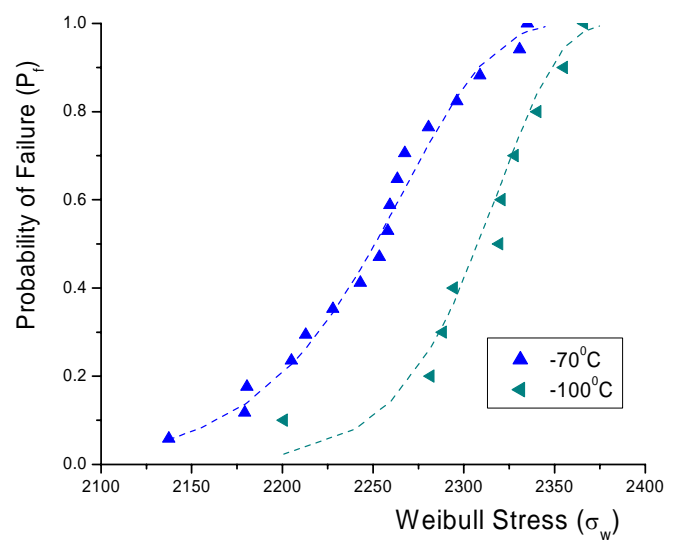

Fig.12 Probability of failure as a function of $\sigma_{\mathrm{w}}$

Table-1 Values of Beremin's parameters for 20MnMoNi55 at two cryogenic temperatures

\begin{tabular}{|c|c|c|}
\hline $\begin{array}{c}\text { Temperature } \\
\left({ }^{\circ} \mathbf{C}\right)\end{array}$ & $\begin{array}{c}\text { Scaling } \\
\text { parameter } \sigma_{\mathbf{u}} \\
(\mathbf{M P a})\end{array}$ & $\begin{array}{c}\text { Corrected shape } \\
\text { parameter } \\
\left(\mathbf{m}_{\text {corrected }}\right)\end{array}$ \\
\hline-70 & 2255.88 & 46.42 \\
\hline-100 & 2329.17 & 60.74 \\
\hline
\end{tabular}


The following two simplified equations have been postulated for determining the Beremin's parameters as a function of temperature for the material $20 \mathrm{MnMoNi5}-5$ using the results quoted in Table- 1 .

$$
\begin{gathered}
\sigma_{u}=3000-3.75 T \\
m=8+300 \exp ^{-\frac{T}{100}}
\end{gathered}
$$

Here $\mathrm{T}$ is the material temperature taken in degree Kelvin. The exponential form of ' $\mathrm{m}$ ' variation confirms rapid increase in ' $m$ ' value towards lower shelf temperatures.

\section{CONCLUSIONS}

Cleavage fracture in low alloy steel usually occurs by unstable micro-cracks initiated at brittle second phase inclusions. Due to scatter in size, orientation and shape of such inclusions and the non-uniform stress field around a loaded crack-tip, the event of cleavage fracture follows a statistical nature. To predict the initiation of such fracture, Beremin's model of cleavage fracture based on weakest link theory has been used using two-parameter Weibull statistics. The procedure adopted during the present work is as follows.

a) A large number of grooved tensile specimens have been fabricated as per standards.

b) The specimens have been tested at $-70^{\circ} \mathrm{C}$ and $-100^{\circ} \mathrm{C}$. Thirty specimens have been tested in each set.

c) The data collected during the tests are (i) specimen temperature, (ii) load-displacement and (iii) images at grooved regions.

d) The images at grooved region have been processed to obtain diametral contraction with loading.

e) Elastic-plastic analyses of test specimens have been performed to shortlist the specimens based on the small difference between the measured maximum load and computed value.

f) The finite element analyses are again performed for these short-listed specimens by adjusting specimen-specific stress-strain curves to match the load v/s diameter contraction accurately up to the point of fracture. The analyses are then used to calculate Weibull stress at fracture.

g) Experimental data has been used to obtain probability of failure as a function of Weibull stresses by ranking the specimens as per increasing diametral strain at failure.

h) Statistical analysis, based on “maximum likelihood method” has been done to determine Beremin's parameters as a function of temperature.

i) Assuming linear variation of ' $\sigma_{\mathrm{u}}$ ' and an exponential change in ' $m$ ' with temperature, coefficients of two equations have been derived based on the present study.

From the results, it is observed that the Beremin's parameters are temperature dependent. Both the parameters decrease with temperature. A number of tests have been also planned at $-150^{\circ} \mathrm{C}$ for the same material to confirm and fine tune the derived constants in the equations of $\sigma_{\mathrm{u}}$ and $\mathrm{m}$ as a function of temperature.

\section{ACKNOWLEDGEMENT}

The authors are grateful to Metallurgical Department of Jadavpur University, Kolkata for conducting the tensile tests on round grooved specimens at cryogenic temperatures. Authors also thank Dr.M.Seidenfuss, MPA Stuttgart for a useful discussion on the present work during his visit to BARC.

\section{REFERENCES}

1. Landes, J.D., Shaffer, D.H., Fracture Mechanics, Twelfth Conference, ASTM STP 700, pp.368-382, Philadelphia, 1980.

2. Beremin, F.M., Metallurgical Transactions A, Vol. 14A, 1983, pp. 2277-2287.

3. Khalili, A., Kromp, K., Journal of Material Science, Vol. 26, 1991, pp. 6741-6752.

4. Miami, F., Bruckner, F., Munz, D., Trolldenier, B., International Journal of Fracture, Vol. 54, 1992, pp. $197-210$.

5. B.K.Dutta, S.Guin, M.K.Sahu, M.K.Samal, “TEMPERATURE DEPENDENCY OF BEREMIN'S PARAMETERS FOR 20MnMoNi5-5 MATERIAL”, Proceedings of ICONE14, 14th International Conference on Nuclear Engineering, Miami, USA, July 2006.

6. G. Bernauer, W. Brocks, Internal Report, Numerical Round Robin on Micro-Mechanical Models, Phase-II, GKSS Research Centre Geesthacht, Germany, June 2000. 